\title{
Influence of silane on the structure of polystyrene prepared by sol-gel coatings via UV curing
}

\author{
Senay Balbay ${ }^{1, *}$, and Caglayan Acıkgoz ${ }^{2}$ \\ ${ }^{1}$ Bilecik Seyh Edebali University, Vocational School. Department of Chemical Technologies, \\ 11030 BİLECIK, Turkey \\ ${ }^{2}$ Bilecik Seyh Edebali University, Faculty of Engineering, Department of Chemistry and Process \\ Engineering, 11030 BİLECIK, Turkey
}

\begin{abstract}
Light, heat, oxygen, moisture, ozone, atmospheric pollution and biological effects are the most important effectives wreak to chemical degradation in the polymer structure. In result of chemical degradation on the polymer consist of problems such as discoloration, brittleness, surface cracks, perspiration, crumbling, smell, surface acidity. In this work, it is aimed to improve the problem of the polystyrene (PS) material against chemical degradation. For this reason, PS is coated with silica sol-gel hybrid coating. Silica sol-gel was synthesized by using vinyltrimethoxysilane (VTMS) as a cross-linker and tetraethylorthosilicate (TEOS) as a silica source. Firstly, four different pre-treatment technique (oven, vacuum oven, lyophilizer and freezing) was studied to determine the most suitable pre-treatment technique for coating on PS substrate of sol-gel prepared with initial formulation (S1). A freezing technique gave the best results for coating sample. The change of surface colour of coated PS was measured by CIE L*a*b* methods. Secondly, the most suitable curing agent (Irgacure 184, Irgacure 819, Darocur 1173 and $\mathrm{TiO}_{2}$ as crystalline anatase phase) was determined to coat the sol-gel on PS. It was determined to the lowest yellowing of PS surface hybrid coated as UV curing of TEOS sol modified by VTMS and $\mathrm{TiO}_{2}$ as photo-initiators. Finally, the chemical and morphological structure of the coated PS samples was determined by FT-IR and SEM instruments,respectively.
\end{abstract}

\section{Introduction}

Today plastic materials are widely used similarly by the automotive, building, white goods and household appliance industry, with a use that has constantly grown over the last few years. The use of plastics in building applications is popular in the developing world because of the low cost and the ease of use of plastic components compared to other materials. One of the disadvantages of using polymers is that they degrade when they are

*corresponding author: senay.balbay@bilecik.edu.tr 
used in high temperature conditions or in outdoor applications. When polymers are used in outdoor applications, the environment negatively influences the servicelife. Polymer degradation can be caused by heat (thermal degradation), light (photodegradation), ionizing radiation (radio degradation), mechanical action or by fungi, bacteria, yeasts, algae and their enzymes (biodegradation)[1].Plastics sensitive to high temperatures (e.g. PMMA, PET) have to be coated by UV-curing systems since the thermally cured systems described show only poor results when cured below $100^{\circ} \mathrm{C}$ [2].Today's hybrid coatings are among other methods also prepared by the sol-gel process used of silica aerogels (silica nanoparticles, siliconalkoxides) and used for many different applications in material science and engineering [3]. Hybrid materials for coating applications can exhibit properties such as optical transparency, specific electrical and mechanical behavior, thermal and weathering resistance, abrasion and impact resistance [4].

Feng et all were studied an immunoassay for bisphenol a based on direct hapten conjugation to the polystyrene surface of micro titer plates. Recoveries were between $70 \%$ and $142 \%$ [5]. Deng et all were presented A facile method of coating polystyrene (PS) particles with organo-silica and their functionalization. By adding the organo-silane precursor into PS aqueous solution in presence of ammonia, an organo-silica shell could be coated on PS particles directly [6].

The object of this study was to improve the ability to yellowing of PS against chemical degradation by coating on PS substrate of the silica sol-jellies synthesized using tetraethylorthosilicate(TEOS) as silica source and vinyltrimethoxysilane (VTMS) as coupling agent.

\section{Experimental}

Materials: Titanium (IV) isopropoxide $\operatorname{Ti}\left[\mathrm{OCH}\left(\mathrm{CH}_{3}\right)_{2}\right]_{4}$ as crystalline anatase phase was supplied by Fisher Scientific. TEOS (tetraethylorthosilicate) as silica source and vinyltrimethoxysilane (VTMS) as coupling agent were provided by abcr - Gute Chemie. Darocur 1173 (2-hydroxy-2-methyl-1-phenylpropan-1-one), Irgacure 184 (1 hydroxycyclohexyl phenyl ketone) and Irgacure 819 (phosphine oxide, phenyl bis(2,4,6-trimethyl benzoyl) as photoinitiator were provided by Ciba Specialty Chemicals.

Table 1. Formulation of UV-curable hybrid coatings.

\begin{tabular}{|c|c|c|c|c|c|}
\hline Components & S1 & S2 & S3 & S4 & S5 \\
\hline TEOS $(\mathrm{ml})$ & 1.85 & 3.70 & 3.70 & 3.70 & 3.70 \\
\hline VTMS $(\mathrm{ml})$ & 1.85 & - & - & - & - \\
\hline $\mathrm{C}_{2} \mathrm{H}_{5} \mathrm{OH}(\mathrm{ml})$ & 9.8 & 9.8 & 9.8 & 9.8 & 9.8 \\
\hline $1 \mathrm{M} \mathrm{HCl}(\mathrm{ml})$ & 1.4 & 1.4 & 1.4 & 1.4 & 1.4 \\
\hline $\mathrm{H}_{2} \mathrm{O}(\mathrm{ml})$ & 0.8 & 0.8 & 0.8 & 0.8 & 0.8 \\
\hline Irgacure $184(\mathrm{~g})$ & 1 & 1 & - & - & - \\
\hline Irgacure $819(\mathrm{~g})$ & - & - & 1 & - & - \\
\hline Darocur $1173(\mathrm{~g})$ & - & - & - & 1 & - \\
\hline $\mathrm{TiO}_{2}(\mathrm{~g})$ & - & - & - & - & 1 \\
\hline $1 \mathrm{M} \mathrm{NH}_{4} \mathrm{OH}(\mathrm{ml})$ & 1.6 & 1.6 & 1.6 & 1.6 & 1.6 \\
\hline
\end{tabular}


Hybrid sol synthesis: The sol-gel precursor was prepared by using TEOS, VTMS, ethanol as solvent, distilled water for hydrolysis, $1 \mathrm{M} \mathrm{HCl}$ as a catalyst, $1 \mathrm{M} \mathrm{NH}_{4} \mathrm{OH}$ for gelling and photo-initiators for UV curing. The compositions of all formulations are also given in Table 1. In the first step of the sol synthesis, partial hydrolysis and condensation of the organoalkoxysilane was carried out under an acid catalysis of $1 \mathrm{M} \mathrm{HCl}$, distilled water, TEOS or VTMS and ethanol with vigorous stirring. The mixing for sol formation was hold at $65^{\circ} \mathrm{C}$ for 3 hours in oven. Secondly, a photo initiator for UV curing put to the mixture. The mixture was magnetically stirred at room temperature. Then $1 \mathrm{M} \mathrm{NH}_{4} \mathrm{OH}$ was added to the mixture and stirred at room temperature until a gel solution was obtained. Thirdly, the gel solution for aging was washed with $5 \mathrm{ml}$ distilled water and put on $4 \mathrm{ml}$ ethanol to solution. Then, the solution was aged at $40^{\circ} \mathrm{C}$ for 3 days in oven [7].

Coating procedure: Polystyrene(PS)test substrates $(75 \mathrm{~mm} \times 100 \mathrm{~mm} \times 4 \mathrm{~mm})$ were used as substrates in all coating applications. Surface of polystyrene test substrates were cleaned with methanol prior to coating. Five formulations represented in Table1 were applied on the PS substrates using an applicator. The pretreatment technique was carried out to the coating substrates and the substrates were irradiated by using a high pressure UV-lamp [(Osram, $300 \mathrm{~W})$, radiation intensity of $1.55 \mathrm{~W} / \mathrm{m}^{2} / \mathrm{nm} . \Lambda \max =340 \mathrm{~nm}$ ] at $40^{\circ} \mathrm{C}$ for 1 hour.

Method: Experimental studies were carried out in two series studies. Firstly, four different pre-treatment technique (oven, vacuum oven, lyophilizer and freezing) was studied to determine the most suitable pre-treatment technique for coating on PS substrate of sol-gel prepared with initial formulation (S1). The change of surface colour of coated PS was measured by CIE L*a*b* methods. The oven pre-treatment was carried out at $60^{\circ} \mathrm{C}$ for 24 hours. The vacuum oven pre-treatment was carried out at $40^{\circ} \mathrm{C}$ for 24 hours. The lyophilizer pre-treatment was applied for 24 hours. The freezing pre-treatment was performed at $-80^{\circ} \mathrm{C}$ for 24 hours. Secondly, the most suitable curing agent (Irgacure 184, Irgacure 819, Darocur 1173 and $\mathrm{TiO}_{2}$ as crystalline anatase phase) was determined to coat the sol-gel on PS. The uncoated PS substrate was determined which yellowing for 26 hours by using ATLAS UV test. For this reason, the yellowing analysis for 26 hours by using ATLAS UV test was applied to the all coating substrates. Finally, surface chemical modification, surface morphology and change of surface colour of coated PS samples were determined by FT-IR, SEM and CIE L*a*b* methods spectrophotometer, respectively.

Characterization: The colorimetric valuesof yellowing color changes of virgin PS (PS), yellowing virgin PS(YPS) and after yellowing analysis and curing of the hybrid material coating test substrates (PS-S1 $1_{\text {oven }}, \mathrm{PS}-\mathrm{S} 1_{\text {vacuum oven }}, \mathrm{PS}-\mathrm{S} 1_{\text {lyophilizer, }}, \mathrm{PS}-\mathrm{S} 1_{\text {freezing, }}, \mathrm{PS}-\mathrm{S} 2$, PS-S3, PS-S4, PS-S5)in theCIE Lab color space were measured by on a Color-Eye automatic differential colorimeter (CM-2600d. Konica Minolta Optics Inc. Japan). The color difference between the test substrates was calculated by the formula $\Delta \mathrm{E}=\left[(\Delta \mathrm{L} *)^{2}+(\Delta \mathrm{a} *)\right.$ $\left.{ }^{2}+\left(\Delta \mathrm{b}^{*}\right)^{2}\right]^{1 / 2} . \Delta \mathrm{L} *=\mathrm{L}_{\text {ref }}-\mathrm{L}_{\text {coated. }}, \Delta \mathrm{a} *=\mathrm{a}_{\text {ref }}-\mathrm{a}_{\text {coated }}, \Delta \mathrm{b} *=\mathrm{b}_{\text {ref }}-\mathrm{b}_{\text {coated }}$ (ref: reference sample and coated: coated PS) [8]. In this color measurement system, parameter L is the color lightness $(\mathrm{L}=0$ for black and $\mathrm{L}=100$ for white), $\mathrm{a}$ is the green $(-) / \operatorname{red}(+)$ axis, and $\mathrm{b}$ is the blue(-)/yellow $(+)$ axis[9].Changes of chemical structure of PS, YPS andPS-S $1_{\text {oven, }}$, PS-S1 $1_{\text {vacuum oven, }}$ PS-S $1_{\text {lyophilizer }}$, PS-S1 $1_{\text {freezing, }}$ PS-S2, PS-S3, PS-S4, PS-S5were determined by ATR-FTIR spectroscopy. Spectra were measured in the range of 400 to $4000 \mathrm{~cm}^{-1}$ with a Perkin Elmer Spectrum 100 instrument. The morphological structure of PS, YPS and PS-S1 $1_{\text {oven }}, \mathrm{PS}-\mathrm{S} 1_{\text {vacuum oven, }}$ PS-S1 $1_{\text {lyophilizer }}, \mathrm{PS}-\mathrm{S} 1_{\text {freezing, }}$ PS-S2, PS-S3, PS-S4, PS-S5 were studied using the following electron microscopes: SEM-ZEISS Supra 40VP. 


\section{Results and Discussion}

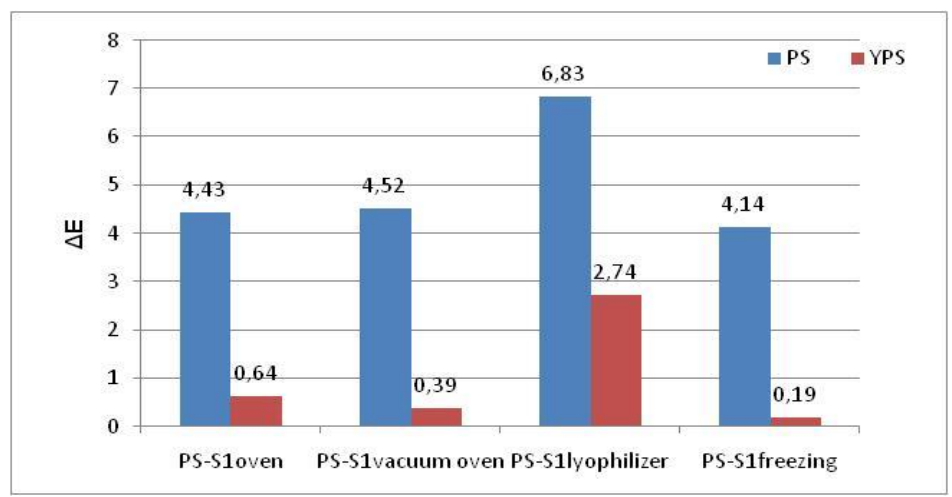

Fig. 1. Colour differences of hybrid coatings of the pre-treatment techniques (to PS and YPS).

Color differences on hybrid coatings of the pre-treatment techniques are showed in Fig. 1.The colorimetric values of yellowing color changes of virgin PS (PS), yellowing virgin PS(YPS) and coated on PS substrate of sol-gel prepared with initial formulation (PS-S1) were measured. $\Delta \mathrm{E}$ value according to PS of YPS was determined as 4.24. The $\Delta \mathrm{E}$ value of $\mathrm{PS}-\mathrm{S} 1_{\text {freezing }}$ according to PS is lower than the $\Delta \mathrm{E}$ value of YPS according to PS. In addition, the $\Delta \mathrm{E}$ value of PS-S1 freezing according to YPS is the lowest according to $\Delta \mathrm{E}$ value of other pre-treatment applications.

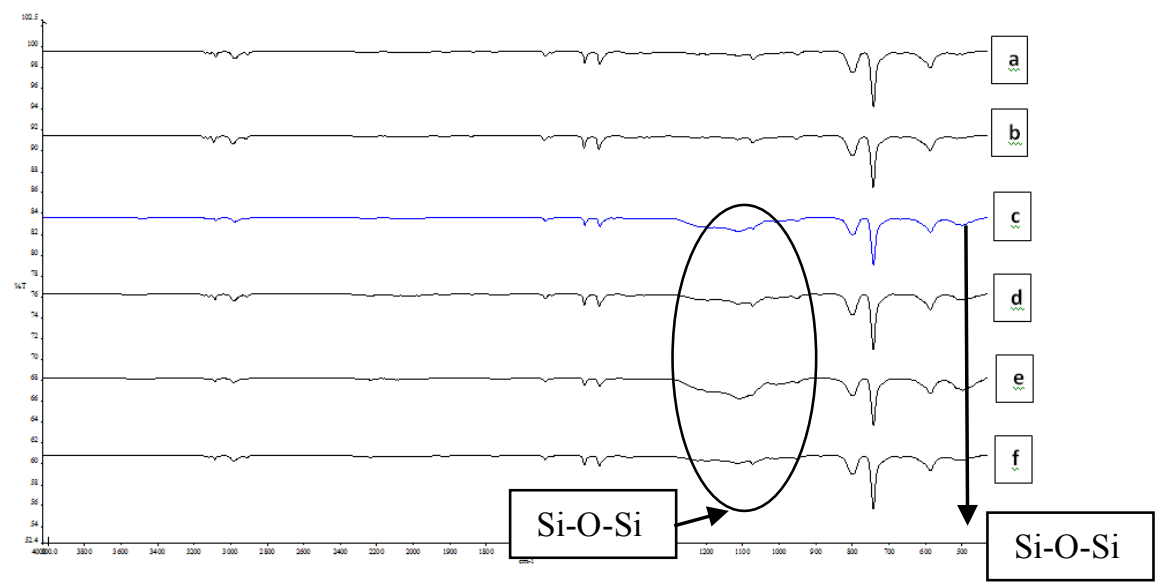

Fig. 2. FT-IR spectra of hybrid coatings of the pre-treatment techniques (a: PS, b:YPS, c: PS-S1 oven, d: PS-S1 $1_{\text {vacuum oven, }}$ e:PS-S1 $1_{\text {lyophilizer, }}$ f: PS-S1 $1_{\text {freezing }}$ )

FT-IR spectra of hybrid coatings of the pre-treatment techniques are given in Fig. 2. The characteristic stretching vibration and bending vibration peaks of $\mathrm{Si}-\mathrm{O}-\mathrm{Si}$ occurred at $1077 \mathrm{~cm}^{-1}$ and $465 \mathrm{~cm}^{-1}$, respectively [15]. These peaks were not observed in the YPS and PS spectra. However, vibration peaks of $\mathrm{Si}-\mathrm{O}-\mathrm{Si}$ were observed in $\mathrm{PS}-\mathrm{S} 1_{\text {oven }}, \mathrm{PS}-\mathrm{S} 1_{\text {vacuum }}$ oven, $\mathrm{PS}-\mathrm{S} 1_{\text {lyophilizer }}, \mathrm{PS}-\mathrm{S} 1_{\text {freezing }}$ surfaces applied of the all pre-treatment. 

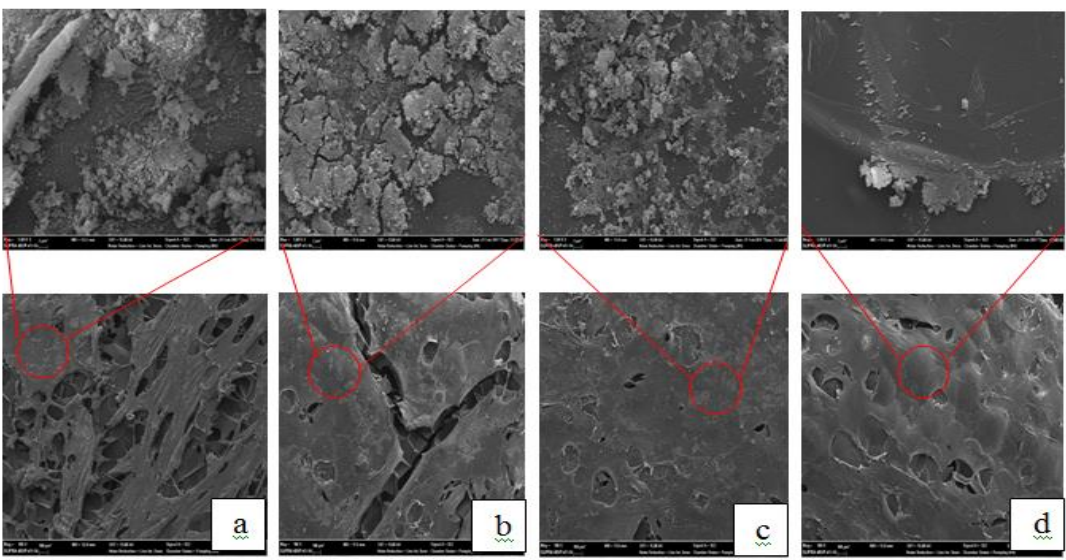

Fig. 3. SEM images of hybrid coatings of the pre-treatment techniques (a: PS-S1 $1_{\text {oven, }}$ b: PS-S1 vacuum oven, c:PS-S1 1yophilizer, d: PS-S1 freezing and top: 5000 mag., bottom: 100 mag.).

SEM images of hybrid coatings of the pre-treatment techniques are given in Fig. 3. Accordingly, it was observed to more homogenous of PS-S1 $1_{\text {freezing }}$ surface applied of the freezing pre-treatment.

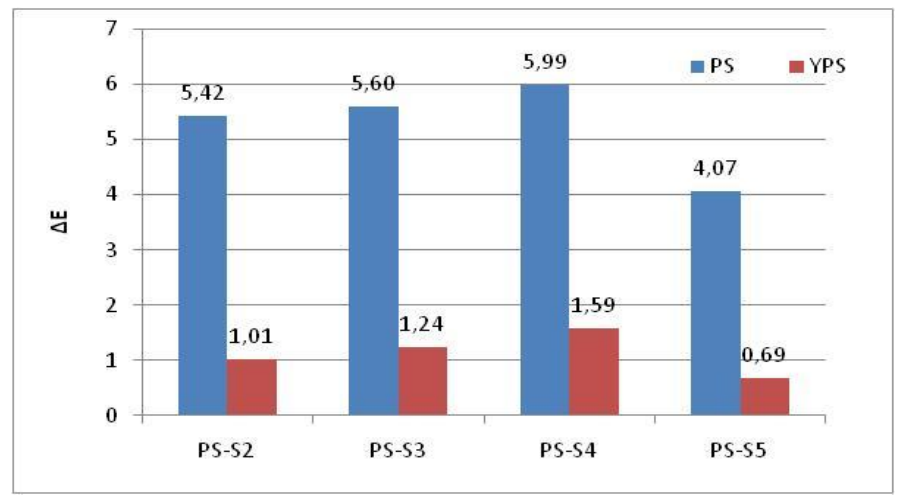

Fig. 4. Colour difference of the photo-initiator for UV curing on hybrid coatings (to PS and YPS).

Color differences of the photo-initiator for UV curing on hybrid coatings are showed in Fig. 4. $\triangle \mathrm{E}$ value of PS-S5 used of $\mathrm{TiO}_{2}$ as photo-initiator according to PS and also YPS has the lowest value.

FT-IR spectra of hybrid coatings of the different photo-initiators for UV curing are given in Fig. 5. The vibration peaks of $\mathrm{Si}-\mathrm{O}-\mathrm{Si}$ were also observed in PS-S5 surfaces prepared with different photo-initiators as well as PS-S1 $1_{\text {oven }}, \mathrm{PS}-\mathrm{S} 1_{\text {vacuum oven, }}, \mathrm{PS}-\mathrm{S} 1_{\text {lyophilizer, }}$ $\mathrm{PS}-\mathrm{S} 1_{\text {freezing }}$ surfaces applied of the all pre-treatment. 


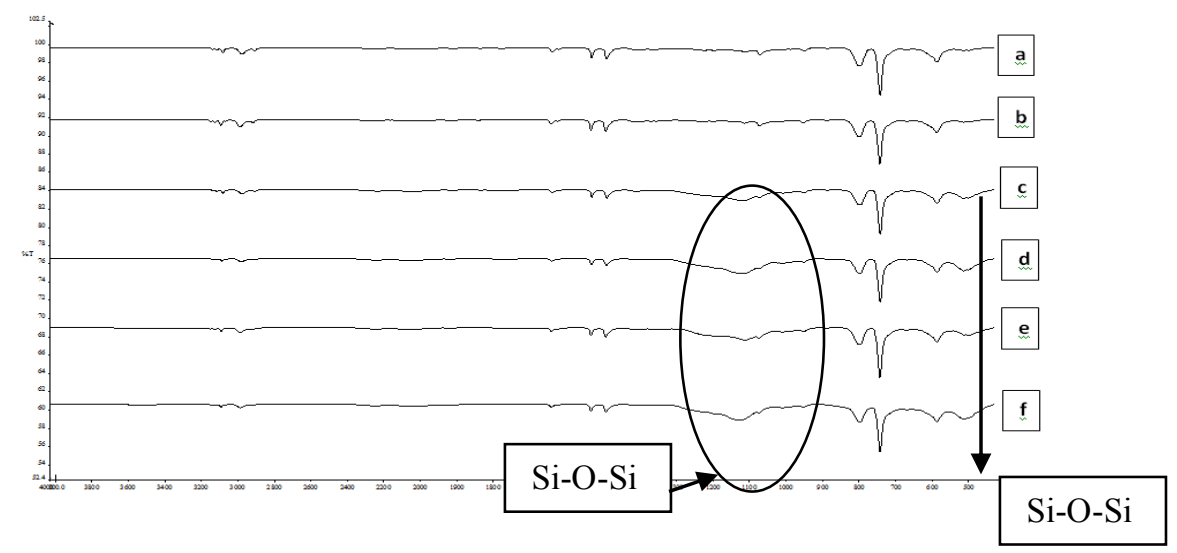

Fig. 5. FT-IR spectra of hybrid coatings of the different photo-initiators for UV curing (a: PS, b: YPS, c: PS-S2, d: PS-S3, e:PS-S4, f: PS-S5).
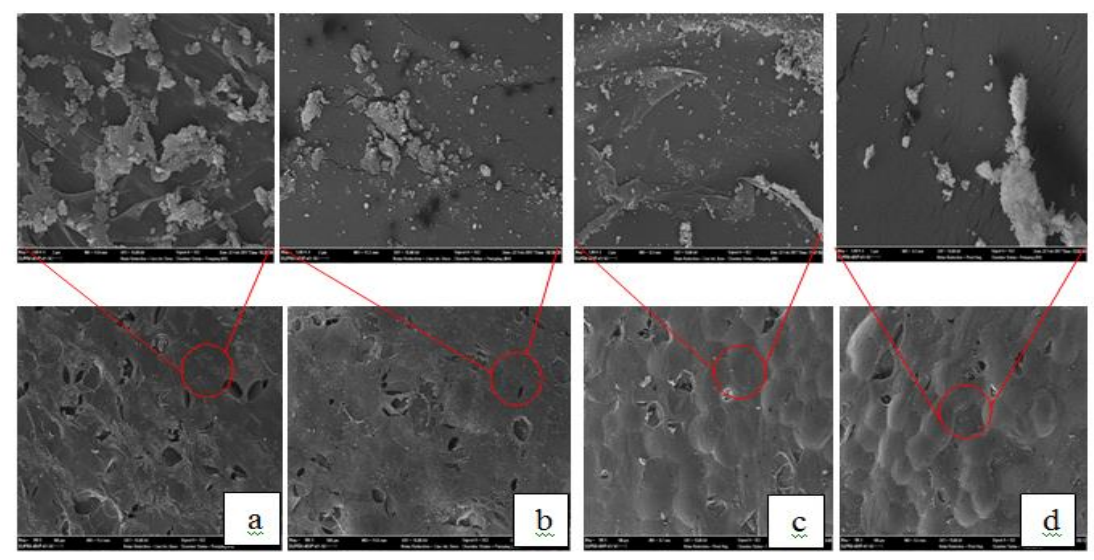

Fig. 6. SEM images of hybrid coatings of the different photo-initiators for UV curing (a: PS-S2, b: PS-S3, c:PS-S4, d: PS-S5 and top: 5000 mag., bottom: 100 mag.).

SEM images of hybrid coatings of the different photo-initiators for UV curing are given in Fig. 6. Accordingly, it has been observed more homogeneous surface in PS-S5 used of $\mathrm{TiO}_{2}$ as a photo-initiators.

Colour differences in PS surfaces of yellowing analysis and coated from only TEOS sol and TEOS sol modified by VTMS are given Fig 7.AE value of PS-S5 by TEOS sol as a silica source according to PS is lower than $\triangle \mathrm{E}$ value of PS-S1 by TEOS sol modified VTMS as coupling agent according to PS. However, when $\triangle \mathrm{E}$ values of the hybrid coating are compared with $\triangle E$ value of YPS, $\triangle E$ value of PS-S1 by TEOS sol modified VTMS is lower. In study, Aydemir was determined that surface roughness had a significant effect on color change [10]. $\triangle \mathrm{E}$ value of PS-S1 by TEOS sol according to PS is low due to the roughness of the cracks on the surface. 


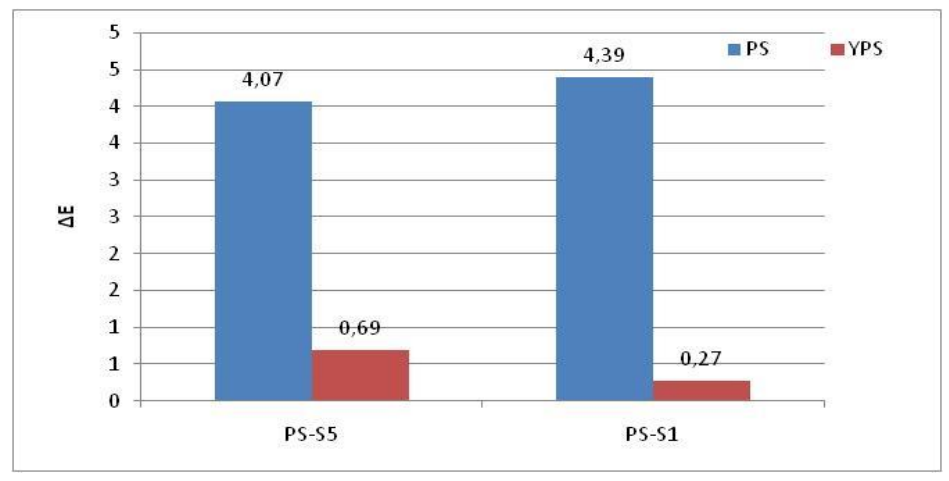

Fig. 7. Colour differences of the TEOS sol (PS-S5) and TEOS sol modified by VTMS(PS-S1) (to PS and YPS).

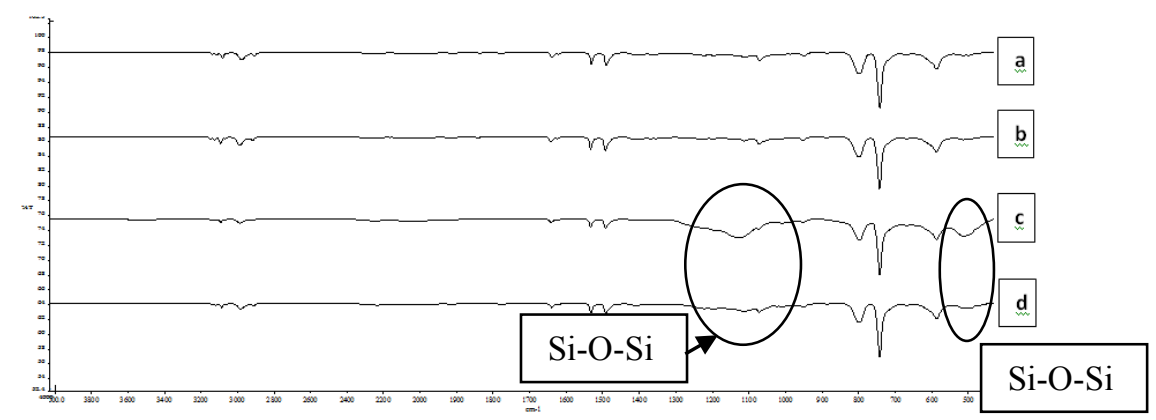

Fig. 8. FT-IR spectra of hybrid coatings of TEOS sol and TEOS sol modified by VTMS (a: PS, b: YPS, c: TEOS(PS-S5), d: TEOS+VTMS(PS-S1)).

FT-IR spectra of hybrid coatings of TEOS sol and TEOS sol modified by VTMS are showed in Fig 8. It was observed that the vibration peaks $\mathrm{Si}-\mathrm{O}$ - Si were more significant in PS-S5surfaces prepared with TEOS sol in Fig 8( c ). Xiao and Hao determined that the vibration peaks $\mathrm{Si}-\mathrm{O}$ - Si were more specifically to not occur of three dimensional network in nano silica sol modified by 3-Trimethoxysilyl-propyl methacrylate (TMSPM) as silicon coupling agent [11]. In Fig. 8d was observed that the vibration peaks $\mathrm{Si}-\mathrm{O}-\mathrm{Si}$ were less obvious in PS-S1 by TEOS sol modified by VTMS. This shows to occur of three dimensional network in PS-S1 by TEOS sol modified by VTMS. 


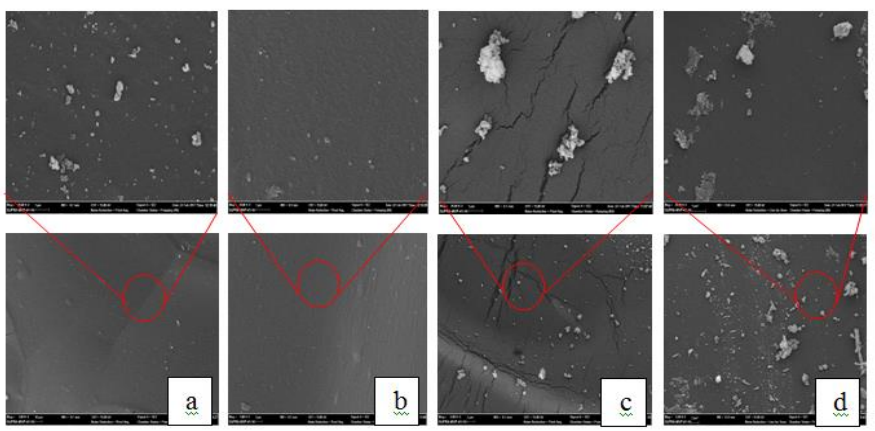

Fig. 9. SEM images of hybrid coatings of TEOS sol (PS-S5) and TEOS sol modified by VTMS (PS-S1)(a: PS, b: YPS, c: TEOS, d: TEOS+VTMS and top: 20000 mag., bottom: 5000 mag.).

SEM images of hybrid coatings of TEOS sol and TEOS sol modified by VTMS are given in Fig 9. Accordingly, it was determined that cracks were formed on surface of PS-S5 by TEOS sol. It has been observed that a crackless and homogeneous surface formed on surface of PS-S1 by TEOS sol modified by VTMS as coupling agent.

\section{Conclusion}

This study was to improve the ability to yellowing of PS against chemical degradation by coating on PS substrate of the silica sol-jellies synthesized using tetraethylorthosilicate (TEOS) as silica source and vinyltrimethoxysilane (VTMS) as coupling agent. It was determined to the lowest yellowing of PS surface hybrid coated as UV curing of TEOS sol modified by VTMS and $\mathrm{TiO}_{2}$ as photo-initiators. In result of yellowing analysis, this hybrid coating is crack-free and homogenous due to effect cross-linking of VTMS. Plastic materials such as PS have low surface energy, surface energies are increased by corona application before bonding or coating process. In this study, the hybrid coatings were successfully coated onto the PS surface under UV light without the corona application on the PS surface. The hybrid coated PS of TEOS sol modified by VTMS as applied by freeze pre-treatment and UV curing can be improve that the various degradation problems for different areas used of PS such as automotive, building, white good.

\section{References}

1. E. Yousif, R. Haddad, Yousif and Haddad Springer Plus, 2 (2013)

2. S. Sepeur, N. Kunze, B. Werner, H. Schmidt, UV curable hard coatings on plastics

3. K. Khezri, H. Mahdavi, Microp. and Mesop. Mat. 228 (2016)

4. I. Šlamborová, V. Zajícová, J. Karpíšková, Exnar. P. Mat. Sci. and Eng. C . 33 (2013)

5. Y. Feng, B. Ning, P. Su, H. Wang, C. Wang, F. Chen, Z. Gao, Talanta, 80 (2009)

6. T.S. Deng, H.J Bongard, F. Marlow, Mat. Ch. and Phy. 162 (2015)

7. D. Güler, Gazi University, MSc Thesis (2012)

8. A. Özcan, İstanbul Business Univ. J. of Sci. 14 (2008)

9. C. Liu, M. Ye, A. Han, J. Li, Ceramics Inter. 41 (2015)

10. C. Aydemir, Marmara J. of Sci. 3 (2014)

11. X. Xiao, C. Hao, Colloids and Surfaces A: Phys-ch and Eng. Asp. 359 (2010) 